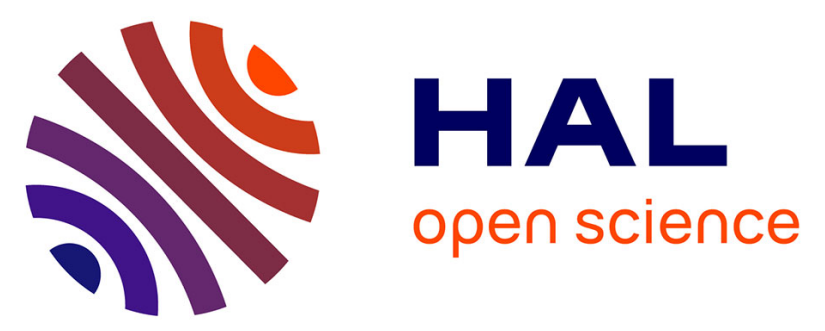

\title{
Toxicological effects of crude oil and oil-dispersant: biomarkers in the heart of the juvenile golden grey mullet (Liza aurata).
}

Thomas Milinkovitch, Nathalie Imbert, Wilfried Sanchez, Stéphane Le Floch, Hélène Thomas-Guyon

\section{To cite this version:}

Thomas Milinkovitch, Nathalie Imbert, Wilfried Sanchez, Stéphane Le Floch, Hélène ThomasGuyon. Toxicological effects of crude oil and oil-dispersant: biomarkers in the heart of the juvenile golden grey mullet (Liza aurata).. Ecotoxicology and Environmental Safety, 2013, pp.8. 10.1016/j.ecoenv.2012.10.029 . hal-01178063

\section{HAL Id: hal-01178063 \\ https://hal.science/hal-01178063}

Submitted on $20 \mathrm{Jul} 2015$

HAL is a multi-disciplinary open access archive for the deposit and dissemination of scientific research documents, whether they are published or not. The documents may come from teaching and research institutions in France or abroad, or from public or private research centers.
L'archive ouverte pluridisciplinaire HAL, est destinée au dépôt et à la diffusion de documents scientifiques de niveau recherche, publiés ou non, émanant des établissements d'enseignement et de recherche français ou étrangers, des laboratoires publics ou privés. 


\section{Toxicological effects of crude oil and oil-dispersant: biomarkers in the heart of the juvenile golden grey mullet (Liza aurata).}

Thomas Milinkovitch ${ }^{1 *}$, Nathalie Imbert ${ }^{1}$, Wilfried Sanchez ${ }^{2}$, Stéphane Le Floch ${ }^{3}$, Hélène Thomas-Guyon ${ }^{1}$

\section{Affiliations}

${ }^{1}$ Littoral Environnement et Sociétés (LIENSs), UMR 7266, CNRS-Université de La Rochelle, 2 rue Olympe de Gouges, F-17042 La Rochelle Cedex 01, France. Email: thomas.milinkovitch01@univ-lr.fr; nathalie.imbert@univ-lr.fr; helene.thomas@univ-lr.fr ${ }^{2}$ Institut National de l'Environnement Industriel et des Risques (INERIS), Unité d'écotoxicologie in vitro et in vivo, Parc Technologique ALATA, F-60550 Verneuil en Halatte, France. Email: wilfried.sanchez@ineris.fr

${ }^{3}$ Centre de Documentation de Recherche et d'Expérimentations sur les Pollutions Accidentelles des Eaux (CEDRE), 715 rue Alain Colas, CS41836-F-29218 Brest Cedex 2, France. Email: stephane.le.floch@cedre.fr

\section{* Corresponding author: T. Milinkovitch}

Littoral Environnement et Sociétés (LIENSs)

UMR 6250, CNRS-Université de La Rochelle 2 rue Olympe de Gouges

F-17042 La Rochelle Cedex 01, France

Email: thomas.milinkovitch01@univ-lr.fr

Tel: +33(0)546507648

Fax: +33 (0)546458264 


\section{Abstract}

Dispersant use is a controversial oil spill response technique in coastal areas. Using an experimental approach, this study evaluated the toxicity of dispersant use upon juveniles of golden grey mullet (Liza aurata). Fish were exposed for 48 hours to either dispersant only, chemically dispersed oil, mechanically dispersed oil, the water-soluble fraction of oil or to control conditions. Following exposure and a depuration period, biomarkers were assessed in fish hearts, namely the total glutathione content and the activity of four enzymes (glutathione S-transferase, superoxide dismutase, catalase and glutathione peroxides). Comparing biomarker responses between the different treatments, this study revealed that 48 hours exposure to dispersed oil (whether mechanically or chemically dispersed) resulted in a toxicity that was still detectable after a 14 days depuration period. Comparing biomarkers responses after an exposure to chemically and mechanically dispersed oil, this study suggests that chemical dispersion of the oil slick would not be more toxic than its natural dispersion under certain turbulent meteorological conditions (e.g. waves). Furthermore, the results indicated that the heart could be a target organ of interest in further studies investigating the toxicity of hydrocarbons. This study, which has been integrated into the DISCOBIOL project (Dispersant et techniques de lutte en milieu côtier: effets biologiques et apport à la réglementation), presents information of interest when attempting to provide a framework for dispersant applications in coastal areas.

Key words: petroleum, dispersant, antioxidant enzyme, glutathione, heart, Liza aurata

\section{Introduction}


Oil spill response techniques have been developed to remediate the ecological consequences of petroleum released into the environment. Dispersant spreading, by boat and/or by plane, is a commonly employed method. According to Chapman et al. (2007), chemical dispersants were used on $18 \%$ of oil spills between 1995 and 2005. This was mainly due to the environmental benefits provided by dispersant application (such as shown in Baca et al., 2005). Indeed, by inducing the transformation of an oil slick on the sea surface into oil droplets in the water column, dispersants: (i) enhance the bacterial degradation of petroleum (Thiem, 1994; Churchill et al., 1995; Swannell and Daniel, 1999); (ii) rapidly dilute the petroleum in the water column, preventing drifting of the oil slick into ecologically relevant shoreline habitats (Merlin, 2005); and (iii) reduce the risk of contamination of organisms dwelling on the sea surface (e.g. seabirds and marine mammals).

In spite of these advantages, certain restrictions are placed on the application of dispersants in European coastal areas. These precautions are based on the low dilution potential of shallow waters in such areas, where the dispersant use could induce high concentrations of hydrocarbons in the water column and, consequently, toxic conditions for aquatic organisms in those areas. This increase in toxicity has been highlighted in many experimental studies. For instance, biomarker approaches demonstrated toxicity in Platichthys flesus (Baklien et al., 1986), Salmo salar (Gagnon and Holdway, 2000), Macquaria novemaculeata (Cohen et al., 2001) and Sebastes schlegeli (Jung et al., 2009) following dispersant use. However, these experimental studies considered the toxicity of chemically enhanced water-accommodated fractions (CEWAF; described in Singer et al., 2000), which did not contain the vast quantities of oil droplets formed in situ during the dispersion of an oil slick. Moreover, recent advancements in chemistry have enabled the creation of new dispersant formulations. These 
so-called 'third generation' dispersants are, in contrast to previous generations, considered intrinsically non-toxic and biodegradable (Merlin, 2005).

In this new context, a study investigating the toxicity of dispersed oil, considering both the recent 'third generation' dispersant formulations and also the presence of oil droplets in the water column, would be of interest. As a consequence, the DISCOBIOL project (Dispersant et techniques de lutte en milieu côtier: effets biologiques et apport à la réglementation) was created to provide information concerning the environmental impact of dispersed oil in coastal areas. The aim of this project was to investigate the potential toxicity and advantages of dispersant use in coastal waters in order to develop a framework for policies on dispersant use. This study evaluates the toxicity of dispersant use in coastal areas by means of an experimental approach. Using a turbulent experimental system, the toxicity of dispersant application was evaluated, taking into account the presence in coastal areas of mixing processes (e.g. waves) which are required for dispersant use (Merlin, 2005). Moreover, to simulate current oil dispersant application, our study used a third generation dispersant, which is the most recent and commonly used of formulations (Merlin, 2005) and is considered as less toxic and more concentrated in tensio-active components than earlier ones. The oil used was a Brut Arabian crude oil considering the important importation of Arabian oils in the European Union in 2011 (European commission directorate-general for energy, http://ec.europa.eu/energy /observatory/oil/import_export_en.htm) and thus its transport along the European coast.

The present study is a part of the DISCOBIOL project. Employing a biomarker approach, it investigated the toxicity of dispersed oil upon juveniles of a pelagic fish species, the golden grey mullet (Liza aurata). This species was chosen because of its significant role in coastal ecosystems, facilitating the transportation of important particulate organic matter from salt marshes to marine coastal waters (Laffaille et al., 1998). Gautier and Hussenot (2005) showed 
the presence of this species in coastal areas during the early part of its life, thus juvenile organisms were chosen.

This ecotoxicological study was conducted at the organ level, on the hearts of fish, since: (i) the toxicological effects of contaminants upon this organ are likely to alter fish survival, a consequence of the heart being a central organ involved in many physiological, immunological and metabolic functions, moving substances such as gases, nutrients, wastes, hormones, antibodies and heat; and (ii) several studies have previously investigated the toxicological effect of hydrocarbons upon this organ, which could, therefore, be considered as a target organ of interest. For instance, Incardona et al. $(2004,2009)$ showed cardiac function defects in fish embryos exposed to hydrocarbons and recently Hicken et al. (2011) showed that sublethal exposure to crude oil during embryonic development alters cardiac morphology. In order to illustrate the toxicological effects of dispersed oil upon the heart, a biomarker approach was used, focussing on the detoxification processes, but also on responses to oxidative stress induced by petroleum hydrocarbons. After exposure to contaminants, oxidative stress is provoked by the formation of reactive oxygen species (ROS; Van der Oost et al., 2003). This phenomenon is likely to induce a loss of structural and/or functional integrity in proteins, lipids and DNA (Winston and Di Giulio, 1991). Consequently, the biomarkers examined during this study were: total glutathione, which is involved in the contaminant detoxification processes (Maracine and Segner, 1998); glutathione S-transferase, which is involved in the detoxification processes and also in antioxidant responses (Van der Oost et al., 2003); and superoxide dismutase, catalase and glutathione peroxidase, which indicate antioxidant responses in hydrocarbon-contaminated fish (Pan et al., 2005; Oliveira et al., 2008; Nahrgang et al., 2009; Hannam et al., 2010). These biomarkers were considered suitable for this investigation as many previous studies have shown them to respond to petroleum contamination and especially to the PAHs (polycyclic aromatic hydrocarbons) 
contained in petroleum (Avci et al., 2005; Almroth et al., 2008; Oliveira et al., 2008; Jung et al., 2009; Kopecka-Pilarczyk and Correia, 2009; Nahrgang et al., 2009)

\section{Materials and methods}

\subsection{Chemicals}

A Brut Arabian crude oil, containing 54\% saturated hydrocarbons, 34\% aromatic hydrocarbons and $12 \%$ polar compounds, was used for this study. This composition was evaluated by CEDRE (Centre of Documentation, Research and Experimentation on accidental water pollution, Brest, France), a laboratory certified according to ISO 9001 and ISO 14001. The API (American Petroleum Institute) gravity of the oil was 33.

The dispersant, manufactured by Total Fluides and designed for marine environment, was evaluated by CEDRE and was deemed effective enough to be used during oil spills (preliminarily determined using the NF.T.90-345 method, see Bocard, 1986 for a more detailed description of this method), non-toxic at the concentration recommended by the manufacturer (preliminarily determined using the standard toxicity test NF.T.90-349) and biodegradable. This dispersant is composed of surfactants (surface active agents) and solvents. As it is a 'third generation' dispersant, the surfactants are blends of anionic and nonionic types. The manufacturer states that the chemical compounds representing a human and aquatic ecosystems health risk are non-ionic surfactants (24\%) and anionic surfactants (between 12 and 24\%).

\subsection{Experimental animals}


153 One hundred Liza aurata juveniles were used for the experiment. They were provided by 154 Commercio Pesca Novellame Srl (Chioggia, Italy). The fish were acclimatized for 3 weeks in

155

$300 \mathrm{~L}$ through-flow tanks containing seawater provided by Oceanopolis (Brest, France) (dissolved oxygen: $91 \pm 2 \%$; salinity: $35 \pm 1 \%$; temperature: $15 \pm 0.1^{\circ} \mathrm{C} ; \mathrm{pH}: 8.01 \pm 0.04$; a photoperiod of 12 hours light/12 hours dark; in seawater free of nitrates and nitrite). During acclimatization they were fed daily with fish food (Neosupra AL3 from Le Gouessant Aquaculture), but were starved for 48 hours prior to the bioassays, and throughout the exposure period, in order to avoid bile evacuation from the gallbladder. At the end of the acclimatization period, just before exposure, their average length was $140.3 \pm 0.11 \mathrm{~mm}$ (mean \pm standard error of the mean, s.e.m.) and their average weight was $38.18 \pm 1.28 \mathrm{~g}$.

\subsection{Experimental system}

The experimental system used, as previously described by Milinkovitch et al. (2011a), was in a temperature controlled room $\left(15^{\circ} \mathrm{C}\right)$. Thus the water temperature for the experiment was 15 $\pm 0.1^{\circ} \mathrm{C}$. Other physicochemical parameters were also measured: $\mathrm{pH}(8.02 \pm 0.07)$ and dissolved oxygen $(95 \pm 1 \%)$ levels remained constant throughout the study. Water was not renewed throughout the experiment. The system was devised to maintain the oil and dispersant mixture as a homogenous solution. Circulation and homogenization of solution in the $300 \mathrm{~L}$ seawater tank was ensured by a funnel linked to a Johnson L450 pump. The solution is sucked up in the funnel, creating a vortex at the surface of the tank, and then expelled at the bottom of the tank after passed through the pump.

\subsection{Exposure treatments}


178 Five exposure treatments were prepared, respecting a protocol previously described in 179 Milinkovitch et al. (2011a, b, 2012). The control exposure treatment (C) was made using seawater provided by Oceanopolis (Brest, France). The mechanically dispersed (MD) oil exposure treatment was made by pouring $20 \mathrm{~g}$ of petroleum in the funnel of the experimental system. The chemically dispersed (CD) oil exposure treatment was made by pouring $20 \mathrm{~g}$ of petroleum in the funnel, as for MD exposure, and $1 \mathrm{~g}$ of dispersant (respecting the $5 \%$ of dispersant recommended by the manufacturer). The dispersant (D) exposure treatment, representing an internal control for $\mathrm{CD}$, was made by pouring $1 \mathrm{~g}$ of dispersant. For the watersoluble fraction of the oil (WSF), in addition to the funnel and the pump, which were kept to maintain the same level of water agitation and circulation as for the other treatments, a $20 \mathrm{~g}$ oil slick was contained using a plastic cylinder $(21 \mathrm{~cm}$ diameter). This treatment differed from the standardized water accommodated fraction (WAF) treatment described by Singer et al. (2000). It was designed to simulate the containment of the oil slick before recovery which is an alternative response technique to dispersant use. During the entire exposure period, the oil slick remained at the surface without mixing and consequently no droplets were observed in the water column, suggesting that the fish were only exposed to the soluble fraction of the oil. For all treatments, the weight of the chemicals masses delivered to the experimental system were determined precisely by mass difference. Twenty grams of oil and $1 \mathrm{~g}$ of dispersant were taken from beakers and delivered (using a glass syringe, VWR international) into the vortex of water created by the funnel linked to the pump.

Although the solutions remained homogenous (less than 5\% difference between three Total petroleum hydrocarbons concentration measurements sampled at three different depths within the experimental tanks), no fish were exposed within 24 hours of the solutions being made. Thereafter, groups of 10 fish were randomly placed in the five experimental tanks $\left(\mathrm{T}_{0}\right)$, which 
each contained one of the exposure treatments described above. The fish were exposed to the various treatments for a period of 48 hours and no fish mortality was observed. The protocol (from the preparation of the exposure treatment to the fish exposure) was replicated, so that a total of 20 fish were subjected to each exposure treatment.

At the end of the exposure period (A), five fish per tank were euthanised using eugenol (4allyl-2-methoxyphenol), while the other five fish were placed in uncontaminated water and fed for 14 days $(\mathbf{B})$. This was performed for both sets of replicates, so that 10 fish per exposure treatment $(\mathrm{C}, \mathrm{CD}, \mathrm{MD}, \mathrm{WSF}$ or $\mathrm{D})$ were euthanised immediately after exposure and 10 fish per treatment were euthanised following the depuration period.

From fish exposed, the hearts were removed and stored at $-80^{\circ} \mathrm{C}$ prior to analysis. The liver and blood were removed and analysed as part of another study (Milinkovitch et al., 2011a) in which information concerning Total petroleum hydrocarbons (TPHs) and PAH concentrations in seawater is available. Thus, the information concerning the present study water contamination is available and discussed in Milinkovitch et al. (2011a) and also summarized in Table 1.

2.5. Measurement of biomarker responses in fish hearts

The hearts were ground in a phosphate buffer (100 mM, pH 7.8) containing $20 \%$ glycerol and $0.2 \mathrm{mM}$ phenylmethylsulfonyl fluoride as a serine protease inhibitor. The homogenates were then centrifuged at $10,000 \mathrm{~g}$ and $4^{\circ} \mathrm{C}$ for 15 minutes to obtain the post-mitochondrial fraction (PMF). Total protein concentrations were determined using the method of Bradford (1992), with bovine serum albumin (Sigma-Aldrich Chemicals, France) as the standard. Prior to the biomarker response measurements, all assays were optimised for juvenile Liza aurata heart samples and adapted for use on a microplate. 
227 Total glutathione (GSHt) concentrations were measured according to the method of 228 Vandeputte et al. (1994). In brief, $10 \mu 1$ of each TCA-deproteinised sample was mixed with a 229 phosphate buffer (100 mM, pH 7.5) containing $10 \mathrm{mM}$ EDTA, $0.3 \mathrm{mM}$ NADPH and $1 \mathrm{mM}$ 230 Ellman reagent. The enzymatic reaction was spectrophotometrically monitored at $405 \mathrm{~nm}$ and 231 the results were expressed in $\mu \mathrm{mol}$ of GSHt/g of protein.

232 Glutathione S-transferase (GST) activity assays were conducted according to the method of Habig et al. (1974). In brief, $20 \mu \mathrm{g}$ of PMF proteins were mixed with a phosphate buffer (100 $\mathrm{mM}, \mathrm{pH}$ 6.5) containing $1 \mathrm{mM}$ chloro dinitrobenzene and $1 \mathrm{mM}$ reduced glutathione. The enzymatic reaction was spectrophotometrically monitored at $340 \mathrm{~nm}$ and the results were expressed in $\mathrm{U}$ of GST/g of protein.

Superoxide dismutase (SOD) activity was measured using the assay developed by Paoletti et al. (1986). In brief, the inhibition of NADH $(350 \mu \mathrm{M})$ oxidation by $11 \mu \mathrm{g}$ of PMF proteins was monitored at $340 \mathrm{~nm}$. For this purpose, PMF proteins were added to a phosphate buffer (100 mM, pH 7.5) with $0.4 \mathrm{mM} \mathrm{NADH}, 6 \mathrm{mM}$ EDTA and $3 \mathrm{mM} \mathrm{MnCl}_{2}$. The results were expressed in $\mathrm{U}$ of $\mathrm{SOD} / \mathrm{mg}$ of protein.

242 Catalase (CAT) activity was monitored using the method previously described by Babo and Vasseur (1992). In brief, $5 \mu \mathrm{g}$ of PMF proteins were mixed (v:v) with a phosphate buffer (100 $\mathrm{mM}, \mathrm{pH} 7.5)$ and $28 \mathrm{mM}$ hydrogen peroxide. The hydrogen peroxide degradation kinetics were assessed at $280 \mathrm{~nm}$ and the results were expressed in $\mathrm{U}$ of CAT/mg of protein.

Glutathione peroxidase (GPx) activity was determined using $30 \mu \mathrm{g}$ of PMF proteins according 247 to the method of Paglia and Valentine (1967). The PMF proteins were added to a phosphate buffer (100 mM, pH 7.6) with $2 \mathrm{mM}$ reduced glutathione, $0.12 \mathrm{mM} \mathrm{NADPH}$ and $2 \mathrm{U} / \mathrm{ml}$ 249 glutathione reductase. Cumene hydroperoxide $(0.55 \mathrm{mM})$ was used as the substrate and enzymatic activity was assessed at $340 \mathrm{~nm}$. The results were expressed in U of GPx/g of 251 protein. 
2.6. Statistical analysis

254

255

Statistical analyses were carried out using Statistica software (version 9). For each variable

(GSHt, GST, SOD, CAT and GPx activities) and each treatment (C, CD, MD, WSF and D)

separately, no significant difference was found (determined with t-tests) between replicates of experiment (described in 2.4.). Normality and homoscedasticity were verified using the Kolmogorov-Smirnov and Cochran tests. For the GSHt concentrations and the GST, SOD,

CAT and GPx activities, two-way factorial analyses of variance (ANOVA) were performed, in order to assess the effects of the different exposure treatments $(C, C D, M D$, WSF and D) after exposure and depuration. For each biological parameter, ANOVA was followed by planned comparison tests (Tukey's HSD test) to detect any significant differences between contamination after exposure and after the depuration period. The significance of the results was ascertained at $\alpha=0.05$. The results were expressed as means \pm s.e.m. (standard error of the mean) of 10 individual fish $(\mathrm{n}=10)$.

\section{Results}

3.1. Total glutathione (GSHt) concentrations in fish hearts

272 The means of the GSHt concentrations, based on 10 individual analyses, showed values of $27354.0 \pm 0.2 \mu \mathrm{mol}$ of GSHt/g of protein (Figure 1) for control Liza aurata, (C) at the end of the 48 hour exposure period (A). The GSHt concentrations in fish hearts showed a significant decrease when the fish were exposed to any of the contaminants (WSF, MD, CD or D). GSHt levels after WSF, MD or CD exposures were half that of the control. The GSHt level 
following dispersant (D) exposure was significantly lower than that of the control, but significantly higher than GSHt levels assessed after WSF, MD or CD exposures.

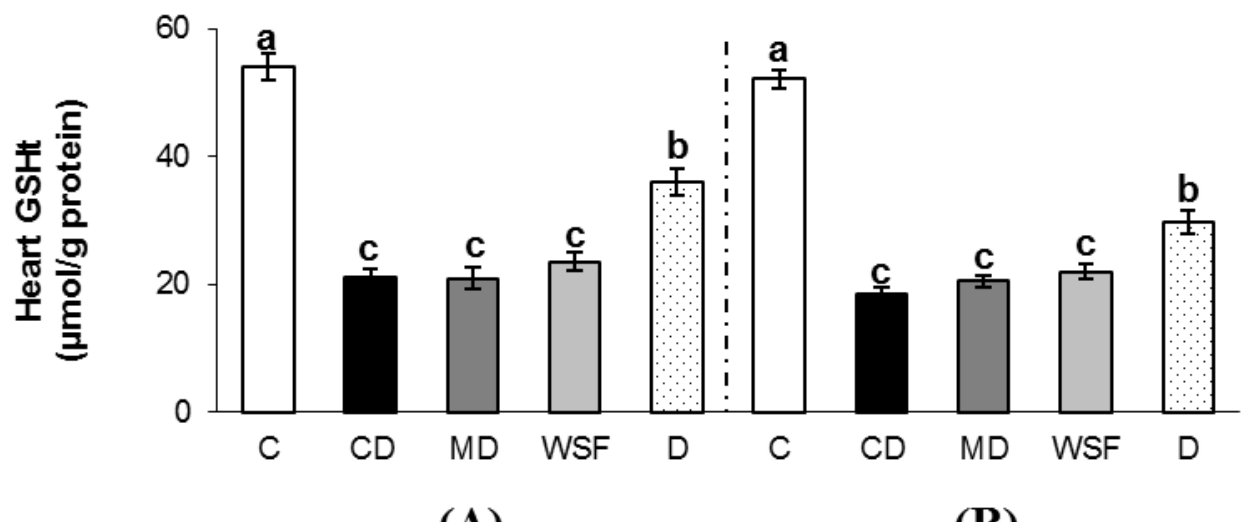

Figure 1: Concentration of total glutathione (GSHt) in the heart of Liza aurata. Glutathione concentration was measured after $48 \mathrm{~h}$ exposure (A) to Control (C), Chemically Dispersed oil (CD), Mechanically Dispersed oil (MD), Water Soluble Fraction (WSF) and Dispersant (D) exposure treatments; and after 14 days of depuration (B) following the exposure: Control (C), Chemically Dispersed oil (CD), Mechanically Dispersed oil (MD), Water Soluble Fraction (WSF) and Dispersant (D). Values represent mean \pm standard error of ten individual analyses ( $n=10$ per treatment). For each period (after $48 \mathrm{~h}$ exposure and after 14 days of depuration), different letters above bars (a, b, c) indicate a significant difference (where $P<0.05$ ). a indicates values significantly not different from control (C) values. $\mathbf{b}$ indicates values significantly different from control $(C)$ values. $\mathbf{c}$ indicates values significantly different from $\mathbf{a}$ and $\mathbf{b}$. For each exposure treatment, ${ }^{*}$ indicates a significant difference $(P<0.05)$ between the values obtained after $48 \mathrm{~h}$ exposure and the values obtained after 14 days of depuration. 
GST activity (Figure 2) in the hearts of the control fish (C) was $366.9 \pm 12.1 \mathrm{U} / \mathrm{g}$ of protein at the end of the 48 hour exposure period (A). No significant increase was observed in fish exposed to the dispersant (D). A significant increase in the activity of this enzyme was observed in fish that were exposed to hydrocarbons: a 70, 72, and $78 \%$ increase for WSF, $\mathrm{MD}$ and $\mathrm{CD}$, respectively. Indeed, compared to the control treatment (C), heart GST activity increased after the fish were exposed to either WSF, MD or CD. Following the 14 day depuration period (B), GST activity levels were still higher in those fish that had been exposed to WSF, MD or CD.

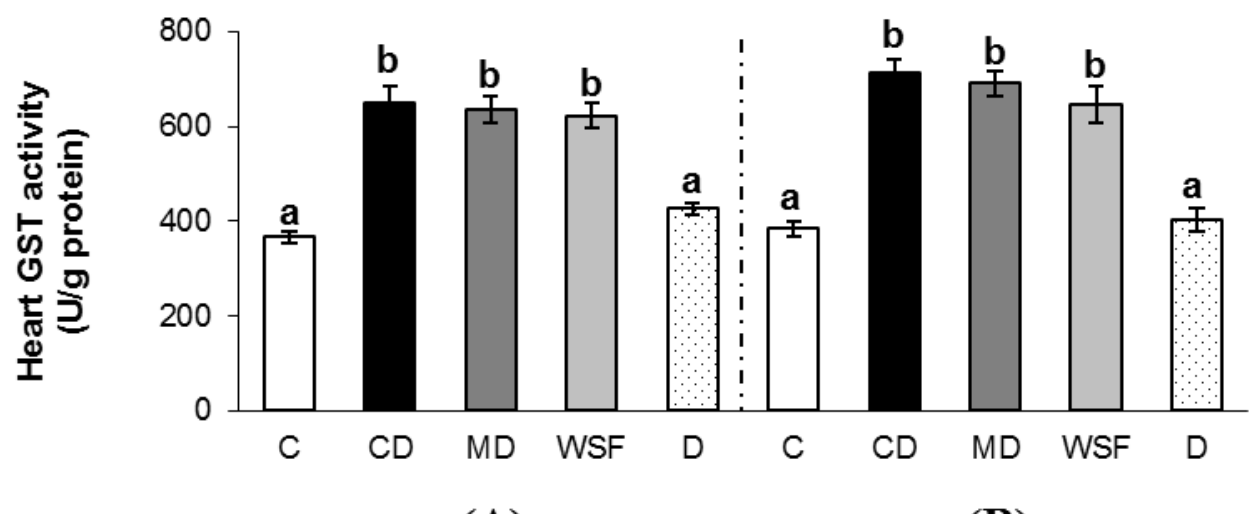

(A)

(B)

Figure 2: Glutathione-S-Transferase (GST) activity in the heart of Liza aurata. Activity was measured after $48 \mathrm{~h}$ exposure (A) to Control (C), Chemically Dispersed oil (CD), Mechanically Dispersed oil (MD), Water Soluble Fraction (WSF) and Dispersant (D) exposure treatments; and after 14 days of depuration (B) following the exposure: Control (C), Chemically Dispersed oil (CD), Mechanically Dispersed oil (MD), Water Soluble Fraction (WSF) and Dispersant (D). Values represent mean \pm standard error of ten individual analyses ( $n=10$ per treatment). For each period (after $48 \mathrm{~h}$ exposure and after 14 days of depuration), different letters above bars $(\mathbf{a}, \mathbf{b}, \mathbf{c})$ indicate a significant difference (where $P<0.05)$. a indicates values significantly not different from control $(C)$ values. $\mathbf{b}$ indicates values significantly different from control (C) values. $\mathbf{c}$ indicates values significantly different from a and $\mathbf{b}$. For each exposure treatment, ${ }^{*}$ indicates a significant difference $(P<0.05)$ between the values obtained after $48 \mathrm{~h}$ exposure and the values obtained after 14 days of depuration

3.3. Superoxide dismutase (SOD) activity in fish hearts 
SOD activity in the hearts of the control (C) Liza aurata was $6.2 \pm 0.2 \mathrm{U} / \mathrm{mg}$ of protein at the end of the 48 hour exposure period (A). SOD activity exhibited a significant increase when fish were exposed to any of the contaminants (WSF, MD, CD or D). For WSF, MD and CD, a significant 82, 52, 70\% increase in SOD activity, was observed (Figure 3), respectively. For the dispersant (D), a 28\% increase in SOD activity was observed, compared to control values. This activity was significantly lower than that measured after WSF, MD or CD exposure. Following the 14 day depuration period (B), a significant decrease in the activity of this enzyme was observed and activity levels of SOD returned to the control values for all exposure treatments.

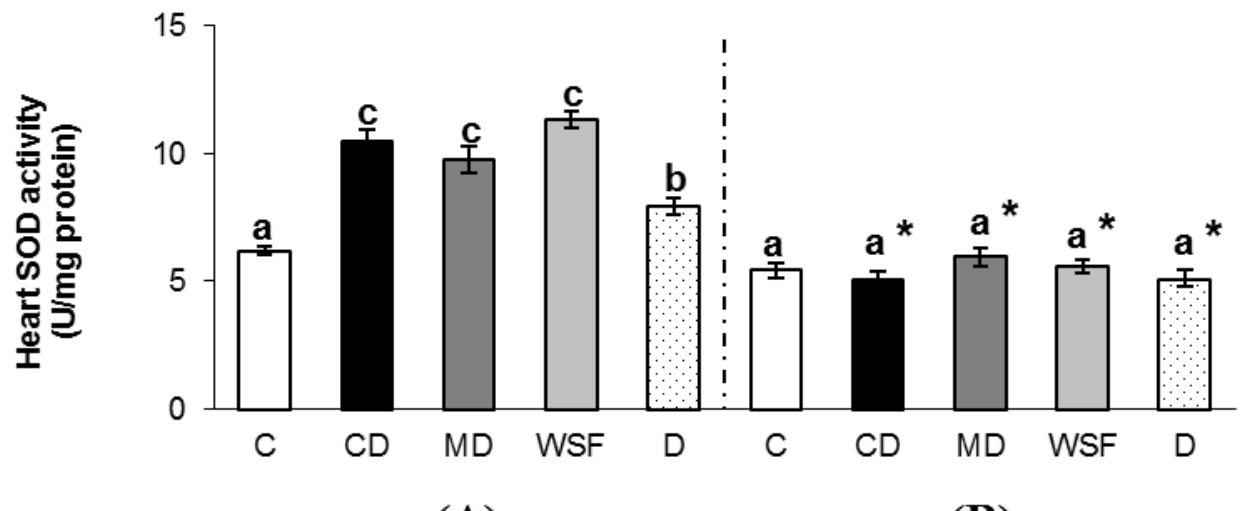

(A)

(B)

Figure 3: SuperOxide Dismutase (SOD) activity in the heart of Liza aurata. Activity was measured after $48 \mathrm{~h}$ exposure (A) to Control (C), Chemically Dispersed oil (CD), Mechanically Dispersed oil (MD), Water Soluble Fraction (WSF) and Dispersant (D) exposure treatments; and after 14 days of depuration (B) following the exposure: Control (C), Chemically Dispersed oil (CD), Mechanically Dispersed oil (MD), Water Soluble Fraction (WSF) and Dispersant (D). Values represent mean \pm standard error of ten individual analyses ( $n=10$ per treatment). For each period (after $48 \mathrm{~h}$ exposure and after 14 days of depuration), different letters above bars $(\mathbf{a}, \mathbf{b}, \mathbf{c})$ indicate a significant difference (where $P<0.05)$. a indicates values significantly not different from control $(C)$ values. $\mathbf{b}$ indicates values significantly different from control (C) values. $\mathbf{c}$ indicates values significantly different from a and $\mathbf{b}$. For each exposure treatment, ${ }^{*}$ indicates a significant difference $(P<0.05)$ between the values obtained after $48 \mathrm{~h}$ exposure and the values obtained after 14 days of depuration. 
3.4. Catalase (CAT) activity in fish hearts

351

352

CAT activity (Figure 4) in the hearts of the control (C) Liza aurata was $253.3 \pm 13.3 \mathrm{U} / \mathrm{mg}$ of protein at the end of the 48 hour exposure period (A). Our results showed that the activity of this enzyme was significantly increased by WSF, MD and CD exposures. The increase was significantly higher $(\mathrm{p}<0.05)$ for fish exposed to CD or MD $(112 \%$ and $132 \%$ increase compared to control values, respectively) than for fish exposed to WSF or D (74\% and 29\% increase compared to control values, respectively). Furthermore, the increase in activity was significantly higher for WSF than for D.

After the 14 day depuration period (B), CAT activity remained unchanged for all exposure treatments (when compared to the levels observed immediately after exposure). The patterns exposed to D.

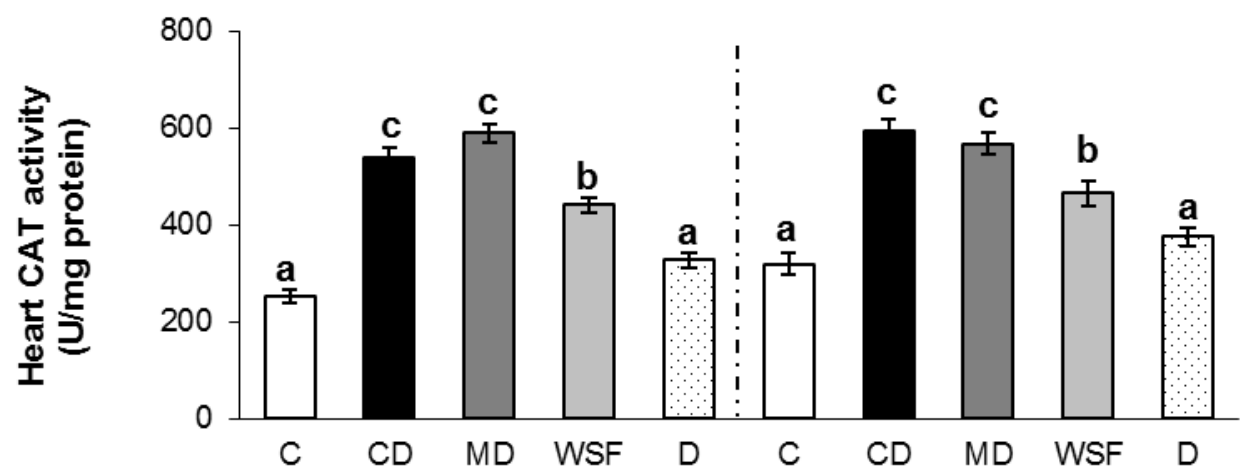

(A)

(B)

Figure 4: Catalase (CAT) activity in the heart of Liza aurata. Activity was measured after $48 \mathrm{~h}$ Soluble Fraction (WSF) and Dispersant (D) exposure treatments; and after 14 days of depuration (B) 
following the exposure: Control (C), Chemically Dispersed oil (CD), Mechanically Dispersed oil (MD), Water Soluble Fraction (WSF) and Dispersant (D). Values represent mean \pm standard error of ten individual analyses ( $n=10$ per treatment). For each period (after $48 \mathrm{~h}$ exposure and after 14 days of depuration), different letters above bars $(\mathbf{a}, \mathbf{b}, \mathbf{c})$ indicate a significant difference (where $P<0.05)$. $\mathbf{a}$ indicates values significantly not different from control (C) values. $\mathbf{b}$ indicates values significantly different from control (C) values. $\mathbf{c}$ indicates values significantly different from $\mathbf{a}$ and $\mathbf{b}$. For each exposure treatment, $*$ indicates a significant difference $(P<0.05)$ between the values obtained after $48 \mathrm{~h}$ exposure and the values obtained after 14 days of depuration.

\subsection{Glutathione peroxidase (GPx) activity in fish hearts}

At the end of the exposure period (A), the GPx activity (Figure 5) was $32.8 \pm 2.2 \mathrm{U} / \mathrm{g}$ of protein in the hearts of the control fish $(\mathbf{C})$. GPx activity displayed the similar pattern of results as those observed for SOD activity: a significant increase in all exposure groups, although this increase was significantly less intense for the D exposure treatment $(65 \%)$ than for the other treatments (WSF 206\%, CD 240\% and MD 253\%). After depuration (B), a significant decrease in activity was observed in the hearts of fish exposed to WSF, CD or MD. However, in spite of this decrease, GPx activity was still higher in fish exposed to CD and MD than in the control.
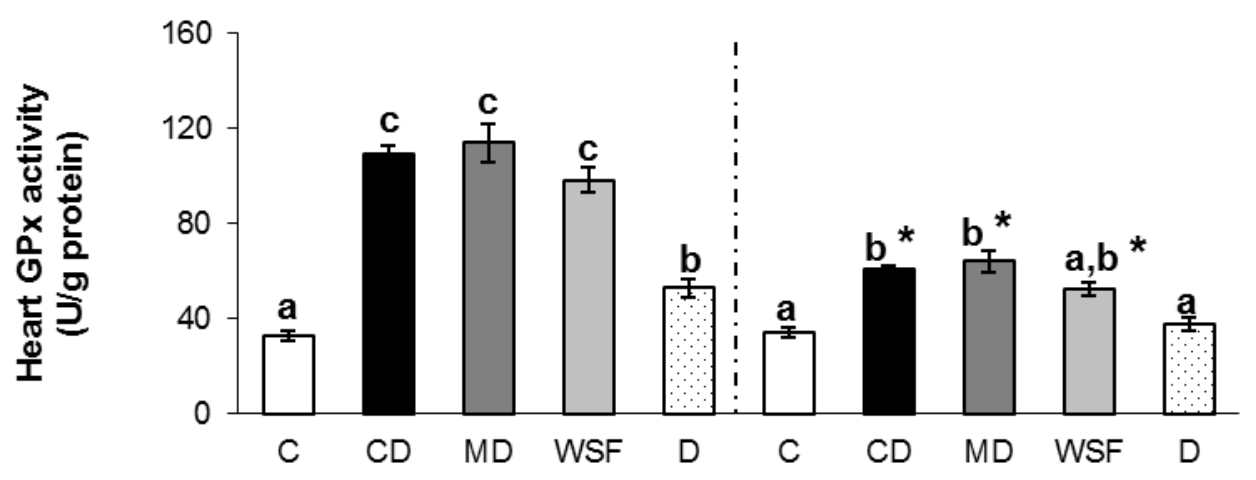

(A)

(B) 
Figure 5: Glutathion peroxidase (GPx) activity in the heart of Liza aurata. Activity was measured after $48 \mathrm{~h}$ exposure (A) to Control (C), Chemically Dispersed oil (CD), Mechanically Dispersed oil (MD), Water Soluble Fraction (WSF) and Dispersant (D) exposure treatments; and after 14 days of depuration (B) following the exposure: Control (C), Chemically Dispersed oil (CD), Mechanically Dispersed oil (MD), Water Soluble Fraction (WSF) and Dispersant (D). Values represent mean \pm standard error of ten individual analyses ( $n=10$ per treatment). For each period (after $48 \mathrm{~h}$ exposure and after 14 days of depuration), different letters above bars $(\mathbf{a}, \mathbf{b}, \mathbf{c})$ indicate a significant difference (where $P<0.05$ ). $\mathbf{a}$ indicates values significantly not different from control $(C)$ values. $\mathbf{b}$ indicates values significantly different from control (C) values. $\mathbf{c}$ indicates values significantly different from a and $\mathbf{b}$. For each exposure treatment, $*$ indicates a significant difference $(P<0.05)$ between the values obtained after $48 \mathrm{~h}$ exposure and the values obtained after 14 days of depuration.

\section{Discussion}

\subsection{Total glutathione content and GST activity in fish hearts}

The results of this study indicated a decrease in GSHt concentrations in fish hearts following all exposure treatments. This decrease of glutathione content has also been observed in the livers of teleost fish after exposure to PAHs (Almroth et al., 2008). However, to our knowledge, few studies have investigated the modulation of total glutathione content in the hearts of fish, making comparison between these results and the literature difficult.

Since total glutathione is considered to be an important molecule in cellular defence against contaminants (Maracine and Segner, 1998), the results of this study suggest that the potential for fish to cope with contaminants is impaired after exposure to WSF, CD, MD or D. Moreover, the results obtained following the depuration period indicated that, in the case of all contaminations, GSHt concentrations had not increased to reach control levels, suggesting repletion had still not occurred after 14 days of depuration. Consequently, even after the depuration period, the potential for the fish to cope with further contaminated environments, such as those present in coastal areas, was still impaired. 
Comparing GSHt levels for the different exposure treatments, our results showed a more profound depletion for $\mathrm{CD}, \mathrm{MD}$ and WSF exposures than for $\mathrm{D}$, suggesting that the toxicological effects of the three exposure treatments containing hydrocarbons were more intense. In parallel, no significant differences between CD, MD and WSF exposures were indicated, suggesting, on the basis of this single result, that the dispersion of the oil, whether mechanically or chemically, did not increase the toxicological effects of the petroleum on the concentration of GSHt.

During contamination, several detoxification processes could involve the use of glutathione. In our study, three hypotheses could explain the decrease in total glutathione: (i) it could be due to an inhibition of the GSH synthesis rate by contaminants, as suggested in Zhang et al. (2004) in goldfish (Carassius auratus); (ii) the heavy metals in petroleum (mainly vanadium and nickel; Salar Amoli et al., 2006) could be chelated by reduced glutathione, leading to GSV or GS-Ni-binding complexes (Sies, 1999), which cannot be assessed through biochemical analysis and consequently contribute to the observed decrease in total glutathione content; (iii) after a phase 1 biotransformation induced by EROD (ethoxyresorufin-O-deethylase) activity, the GST could induce a conjugation of the oxidized PAHs to reduced glutathione (George, 1994). The conjugate could then be excreted, thus leading to a decrease in total glutathione. For dispersant alone (D) the decrease of total glutathione can only be explained by the first hypothesis since dispersant alone contains neither PAHs nor heavy metals. Thus, the reduction of glutathione could be due to the inhibition of the GSH synthesis rate by the dispersant. For fish exposed to CD, MD and WSF, all hypotheses are conceivable. However, our results suggest an intense role of the PAH conjugation. Indeed, for these exposure treatments, the decrease in total glutathione was associated with an increase in GST activity. 
Moreover, the regression between GST activity and glutathione content was tested (data not shown) and found highly significant $(\mathrm{P}<0.001)$.

Comparing the biological effects with the seawater PAH concentrations, this study showed

445 same magnitude of response in the GST activity levels between WSF and either CD and MD treatments while total concentrations of PAHs in $\mathrm{CD}$ and $\mathrm{MD}$ treatments are both approximately 8 and 50 times higher than in WSF, at the beginning $(\mathrm{T} 0=0 \mathrm{~h})$ and at the end of the exposure $(\mathrm{T} 1=48 \mathrm{~h})$ respectively. This could be due to the fact that GST activity in heart reached its maximum with WSF treatment and that consequently a higher load of contamination (through $\mathrm{CD}$ and MD exposure) did not induce a further increase of GST activity. Since GST activity is involved in the depletion of total glutathione, the same magnitude of response of this enzyme for WSF, CD and MD could explain the identical GSHt depletion observed for these three treatments.

\subsection{Activity of antioxidant enzymes in fish hearts}

The results of this study showed an increase in the three enzymes assessed after oil exposure, when compared to the control. This response was previously observed in several ecotoxicological studies and, more specifically, in studies that investigated the toxicological effects of hydrocarbons in teleost fish (Zhang et al., 2004; Sun et al., 2006; Oliveira et al., 2008; Oliva et al., 2010). The enhancement of antioxidant enzyme activities is considered to be a defence mechanism against the production of reactive oxygen species (ROS), initiated by the incorporation of PAHs in the internal environment of organisms (Guenguerich, 1993; Van der Oost et al., 2003).

The antioxidant enzyme activities in fish hearts revealed that CD and MD exposures induced the highest antioxidant responses for SOD, CAT and GPx. These results are in accordance 
with those of Milinkovitch et al. (2011a), since the PAH biliary metabolite concentrations (after 48 hours exposure) indicated that $\mathrm{CD}$ and $\mathrm{MD}$ also induced the highest levels of PAH incorporation. However, although biliary metabolites did not reveal a significant increase in PAH incorporation after WSF exposure in our previous investigation (Milinkovitch et al., 2011 a), the present study showed that the antioxidant response of SOD, GPx and CAT was significantly increased after WSF exposure. This finding suggests that antioxidant activity in fish heart could be a more sensitive biomarker than PAH biliary metabolites in the aim to detect the precocious biological effects of oil.

As previously described (discussing GST activity in 4.1.), the biological effects did not match with the seawater PAH concentrations measurements. Indeed, regarding to SOD and GPx activities, this study did not highlight significant different responses in the antioxidant activities between WSF and either CD and MD treatments while total concentrations of PAHs in $\mathrm{CD}$ and MD treatments are both 8 and 50 times higher than in WSF (at the beginning i.e. $\mathrm{T} 0=0 \mathrm{~h}$ and at the end of the exposure i.e. $\mathrm{T} 1=48 \mathrm{~h}$, respectively). On this basis and analogously to GST activity, it is conceivable to hypothesize that antioxidant activities of SOD and GPx in heart reached their maximum with WSF treatment and that consequently a higher load of contamination (through $\mathrm{CD}$ and $\mathrm{MD}$ exposure) did not induce a further increase of antioxidant activity.

Regarding to CAT activity, results exposed the effects of oil dispersion (whatever mechanically or chemically) since, after depuration, CAT activity was higher for MD and CD exposures than for WSF exposure. However, this statement must be interpreted cautiously since it is based on a single biomarker analysis; 4 of the other 5 biomarkers (GSHt, GST, SOD, GPx) did not highlight significant difference between WSF and either CD and MD exposure. 
After 14 days of depuration, (i) CAT activity was still significant following CD, MD or WSF exposure and (ii) GPx activity was still significant following CD and MD exposures. Thus, in addition to the transitory effects of hydrocarbons observed after acute exposure (48 hours), these results also illustrated the effect of oil after depuration.

Recent studies have suggested a relationship between the impairment of fish survival and the modulation of the antioxidant response. Allen and Moore (2004) revealed links between antioxidant response and the health status of organisms. Tsangaris et al. (2007) found a significant correlation between glutathione peroxidase and the scope for growth in Mytilus edulis contaminated with heavy metals. On this basis, the results presented in this study suggest that fish survival would be impaired after exposure to MD or $\mathrm{CD}$, but impairment could be described as relatively less important following exposure to WSF, since the CAT activity was found to be significantly lower.

Exposure to the dispersant also seems to have induced toxicological effects, indicated by increases in SOD and GPx activities, even though the activities of these antioxidant enzymes did not reach those levels observed after CD, MD or WSF exposure. This result agreed with a recent study of Luna-Acosta et al. (2011) which revealed a modulation of SOD activity in the plasma of oysters, Crassostrea gigas, following dispersant exposure. This study and the present one exposed a modulation of biomarkers and thus highlighted the intrinsic toxicity of dispersant which disagreed with the statement of the manufacturer who claimed that dispersant is non-toxic at the concentration recommended by the manufacturer. This discrepancy could be due to the method used to determine the non-toxicity of the dispersant (NF.T.90-349). Indeed, this standard toxicity test measures the mortality rate of Palaemonetes varians exposed to several concentrations of a dispersant and compares them to the mortality rate observed for a reference toxic compound ( $\mathrm{N}$-alkyl dimethyl benzyl ammonium chloride). However, this toxicity test does not take into account sublethal effects of dispersants. Such 
studies could be of interest in order to better estimate the toxicity levels of individual dispersants.

The antioxidant response suggested the production of ROS, which could potentially result in structural and functional impairments of the heart (Van der Oost, 2003). Thus, in order to better estimate the effects of the exposure treatments, it would be of interest to measure changes in integrity at the cellular and organ levels. For instance, at the cellular level, a comet assay to determine DNA integrity or an MDA (malondialdehyde, a product of oxidative lipid degradation) assay to evaluate lipid peroxidation could be conducted. At the organ level, cardiac performance could also be measured, since it has been suggested that this biological parameter is altered by oxidative stress (Luo et al., 2006). A recent study of Milinkovitch et al. (2012) already investigated the force and the velocity of contraction in golden grey mullets exposed to similar treatments (WSF, D, MD, CD); results showed an impairment of the velocity of contraction for all treatments while no effect on the force of contraction. Similarly, cardiac abnormalities and defects in function could be studied, since Incardona et al. (2004) have already demonstrated a modification of heart morphology in PAH contaminated fish embryos (Danio rerio).

When compared to a previous and similar study (Milinkovitch et al., 2011a), the present results showed that the biomarker responses were more marked in fish hearts than in other target organs, such as the liver. Indeed, in the previous study, after the same exposure treatments $(\mathrm{CD}, \mathrm{MD}, \mathrm{WSF}$ or $\mathrm{D})$, no increases in antioxidant enzyme activities in fish livers were recorded. This is in accordance with Thomaz et al. (2009), who assessed antioxidant enzyme activities in several organs and who also suggested that the heart was more sensitive to the organophosphate insecticide trichlorfon than the liver or the gills. Taken together, these studies suggest that the heart could be considered as a target organ of interest for future 
ecotoxicological studies. This finding agree with a recent study of Milinkovitch et al. (2012) who showed an impairment of cardiac performance in fish exposed to

\section{Conclusions}

The results of this study showed biological responses for all of the biomarkers tested (GSHt, GST, GPx, SOD and CAT) and therefore indicated that the heart could be a target organ of interest when examining antioxidant responses and detoxification processes due to exposure to organic contaminants.

Most of the biomarkers tested (GSHt, GPx, SOD) showed a modulation after exposure to a single dispersant (D), suggested this product has a sublethal toxicity. This disagrees with the acceptance of this 'third generation' dispersant as a non-toxic product. Thus, further studies are required to better estimate its intrinsic toxicity on pelagic organisms.

This study showed significant biomarkers responses after exposure to $\mathrm{CD}$ or $\mathrm{MD}$, therefore suggesting that dispersed oil has toxicological effects. Such biomarkers responses have also been observed following WSF exposure for the biomarkers GSHt, GST, SOD and GPx. However, results showed a significantly lower increase in CAT activity for WSF exposure (compared to MD and CD exposure) which could suggest that an undispersed oil slick would be less toxic to organisms living in the water column than a dispersed one. However, such an interpretation is based on a single biomarker response (on the 5 analysed) which incite us to be cautious. Further studies, for instance at other biological levels, would be recommended in the aim of highlighting the difference of toxicity that could exist between WSF and either CD and MD exposure.

Most of the biomarkers (GSHt, GST, CAT and GPx) did not return to the control levels after 14 days of depuration following the exposure of fish to oil (WSF, MD or CD). Thus, in 
addition to the acute toxicity, oil and dispersed oil induced a toxicity that was still present after the depuration period. The assessment of biomarkers responses on a longer depuration period could provide further information concerning the long-term toxicity of hydrocarbons.

No significant differences were observed between exposure to $\mathrm{CD}$ or MD. The difference between these two treatments is the addition of dispersant for $\mathrm{CD}$ exposure. Thus, extrapolating to the issues involved in oil spill response techniques, these results suggest that when environmental conditions (e.g. waves, wind, swell and tide) already provoke the natural dispersion of the oil slick (simulated by MD exposure), the addition of the dispersant (CD exposure) would not increase the environmental effects of oil. On the other hand, the use of dispersant would reduce the environmental cost of the oil spill by inhibiting the environmental risks associated with the recoalescence of the oil slick (e.g. contamination of sea surface dwelling organisms, or drifting of the oil slick into ecologically relevant shoreline habitats) and by enhancing the bacterial degradation of petroleum.

However, these conclusions should be considered cautiously, since they are based on the study of one species (Liza aurata) in a single compartment (water column). Consequently, the DISCOBIOL project (Dispersant et techniques de lutte en milieu côtier : effets biologiques et apport à la réglementation) intends to perform further studies focussing on several species from coastal areas (Crassostera gigas, Mytilus edulis, Scophtalmus maximus, Dicentrarchus labrax and Liza aurata) and examining the sediment as another compartment of interest.

\section{Acknowledgements}

The Agence Nationale de la Recherche and especially Michel Girin and Gilbert Le Lann are acknowledged for their financial support of the 'DISCOBIOL' project, managed by F.X. Merlin. Special thanks go to Julie Lucas and Marion Menguy for their help and assistance 
590

591

592 Sustainable Development (Programme 190-AP 09-11).

593

594

595

596

597

598

599

600

601

602

603

604

605

606

607

608

609

610

611

612

613

\section{References} and a PAH polluted site. Mar. Environ. Res. 66: 271-277. 105. Environ. Res. 19: 1-11. of rainbow trout (Oncorhynchus mykiss). Aquat. Toxicol. 22: 61-68.

during the study and experimental procedures. This study was supported by a $\mathrm{PhD}$ grant from the Conseil Général of the Charente-Maritime and by the French Ministry for Ecology and

Allen, J.I., Moore, N.M., 2004. Environmental prognostics: Is the current use of biomarkers appropriate for environmental risk evaluation? Mar. Environ. Res. 58: 227-232.

Almroth, B.C., Sturve, J., Stephensen, E., Holth, T.F., Förlin, L., 2008. Protein carbonyls and antioxidant defenses in corkwing wrasse (Symphodus melops) from a heavy metal polluted

Avci, A., Kaçmaz, M., Durak, I., 2005. Peroxidation in muscle and liver tissues from fish in a contaminated river due to a petroleum refinery industry. Ecotoxicol. Environ. Saf. 60: 101-

Baklien, Å., Lange, R., Reiersen, L.O., 1986. A comparison between the physiological effects in fish exposed to lethal and sublethal concentrations of a dispersant and dispersed oil. Mar.

Babo, S., Vasseur, P., 1992. In vitro effects of Thiram on liver antioxidant enzyme activities 
Baca, B., Ward, G. A., Lane, C. H. \& Schuler, P. A., 2005. Net Environmental Benefit

615

616

617

618

619

620

621

622

623

624

625

626

627

628

629

630

631

632

633

634

635

636

637

638

Analysis (NEBA) of dispersed oil on nearshore tropical ecosystems derived from the 20 year

"TROPICS" field study. Proceedings of the 2005 International Oil Spill Conference, 1-4.

Miami, Florida, USA.

Bocard, C., Castaing, G., Ducreux, J., Gatellier, C., 1986. Summary of Protectmar experiments, the French dispersants offshore trial program. Oil and Chemical Pollution, 3: $471-484$.

Bradford, M.M., 1992. A rapid sensitive method for the quantitation of microgram quantities of protein utilizing the principle of protein-dye binding. Analyt. Biochem. 72: 248-254.

Chapman, H., Purnell, K., Law, R.J., Kirby, M.F., 2007. The use of chemical dispersants to combat oil spills at sea: A review of practice and research needs in Europe. Mar. Poll. Bull. 54: 827-838.

Churchill, P.F., Dudley, R.J., Churchill, S.A.,1995. Surfactant-enhanced bioremediation. Waste Manag. 15: 371-377.

Cohen, A., Nugegoda, D., Gagnon, M.M., 2001. Metabolic responses of fish following exposure to two different oil spill remediation techniques. Ecotoxicol. Environ. Saf. 48: 306310. Ecotoxicol

Gagnon, M.M., Holdway, D.A., 2000. EROD induction and biliary metabolite excretion following exposure to the water accommodated fraction of crude oil and to chemically dispersed crude oil. Arch. Environ. Contam. Toxicol. 38: 70-77. 
640 Gautier, D., Hussenot, J., 2005. Les mulets des mers d'Europe. Synthèse des connaissances 641 sur les bases biologiques et les techniques d'aquaculture, Ifremer, Paris.

642

643 George, S.G., 1994. Enzymology and molecular biology of phase II xenobiotic-conjugating 644 enzymes in fish. In: Malins D.C., Ostrander G.K. Aquatic Toxicology. Lewis, Boca Raton, 645 FL, USA, pp. 37-85.

646

647

Guenguerich, F.P., 1993. Cytochrome P450 enzymes. Amer. Sci. 81: 440-447

648

649

Habig, W.H., Pabs, M.J., Jakoby, W.B., 1974. Glutathione S-Transferases. The first 650 enzymatic step in mercapturic acid formation. J. Biol. Chem. 249: 7130-7139.

651

652

Hannam, M.L., Bamber, S.D., Galloway, T.S., John Moody, A., Jones, M.B., 2010. Effects of 653 the model PAH phenanthrene on immune function and oxidative stress in the haemolymph of 654 the temperate scallop Pecten maximus. Chemosphere 78: 779-784.

655

656

Hicken, C.E., Linbo, T.L., Baldwin, D.H., Willis, M.L., Myers, M.S., Holland, L., Larsen, M., 657

Stekoll, M.S., Rice, S.D., Collier, T.K., Scholz, N.L., Incardona, J.P., 2011. Sublethal 658 exposure to crude oil during embryonic development alters cardiac morphology and reduces aerobic capacity in adult fish. Proc. Natl. Acad. Sci. 108: 7086-7090.

660

661

Incardona, J.P., Collier, T.K., Scholz, N.L., 2004. Defects in cardiac function precede 662 morphological abnormalities in fish embryos exposed to polycyclic aromatic hydrocarbons. 663 Toxicol. Appl. Pharmacol. 196: 191-205. 
665 Incardona, J.P., Carls, M.G., Day, H.L., Sloan, C.A., Bolton, J.L., Collier, T.K., Scholz, N.L., 666 2009. Cardiac arrhythmia is the primary response of embryonic pacific herring (Clupea 667 pallasi) exposed to crude oil during weathering. Environ. Sci. Technol. 43: 201-207.

668

669

670

671

672

673

674

675

676

677

678

679

680

681

682

683

684

685

686

687

688

Jung, J.H., Yim, U.H., Han, G.M., Shim, W.J., 2009. Biochemical changes in rockfish, Sebastes schlegeli, exposed to dispersed crude oil. Comp. Biochem. Physiol., Part C: Toxicol. Pharmacol. 150: 218-223.

Kopecka-Pilarczyk, J., Correia, A.D., 2009. Biochemical response in gilthead seabream (Sparus aurata) to in vivo exposure to a mix of selected PAH. Ecotoxicol. Environ. Saf. 72: 1296-1302.

Laffaille, P., Brosse, S., Feunteun, E., Baisez, A., Lefeuvre, J.C., 1998. Role of fish communities in particulate organic matter fluxes between salt marshes and coastal marine waters in the Mont Saint-Michel Bay. Hydrobiol. 374: 121-133.

Luna-Acosta, A., Kanan, R., Le Floch, S., Huet, V., Pineau, P., Bustamante, P., ThomasGuyon, H., 2011. Enhanced immunological and detoxification responses in Pacific oysters, Crassostrea gigas, exposed to chemically dispersed oil. Water Res. 45: 4103-4118

Luo, J., Xuan, Y., Gu, Y., Prabhu, S.D., 2006. Prolonged oxidative stress inverts the cardiac force-frequency relation: role of altered calcium handling and myofilament calcium responsiveness. J. Mol. Cell. Cardiol. 40: 64-75. 
689

690

691

692

693

694

695

696

697

698

699

700

701

702

703

704

705

706

707

708

709

710

711

712

713

Maracine, M., Segner, H., 1998. Cytotoxicity of metals in isolated fish cells: Importance of the cellular glutathione status. Comp. Biochem. Physiol., Part A: Mol. Integr. Physiol. 120: 83-88.

Merlin, F.X., 2005. Traitement aux dispersants des nappes de pétrole en mer. CEDRE, Brest.

Milinkovitch, T., Ndiaye, A., Sanchez, W., Le Floch, S., Thomas-Guyon, H., 2011a. Liver antioxidant and plasma immune responses in juvenile Golden grey mullet (Liza aurata) exposed to dispersed crude oil. Aquat. Toxicol. 101: 155-154.

Milinkovitch, T., Godefroy, J., Théron, M., Thomas-Guyon, H., 2011b. Toxicity of dispersant application: biomarkers responses in gills of juvenile golden grey mullet (Liza aurata). Environ. Pol. 159: 2921-2928.

Milinkovitch, T., Lucas, J., Le Floch, S., Thomas-Guyon, H., Lefrançois, C., 2012. Effect of dispersed crude oil exposure upon the aerobic metabolic scope in juvenile golden grey mullet (Liza aurata). Mar. Pol. Bull. 64: 865-871.

Milinkovitch, T., Thomas-Guyon, H., Lefrançois, C., Imbert, N., 2012. Dispersant use as a response to oil spills: toxicological effects on fish cardiac performance. Fish Pysiol. Biochem DOI 10.1007/s10695-012-9696-z.

Nahrgang, J., Camus, L., Gonzalez, P., Goksøyr, A., Christiansen, J.S., Hop, H., 2009. PAH biomarker responses in Polar cod (Boreogadus saida) exposed to benzo(a)pyrene. Aquat. Toxicol. 94: 309-319. 
715 Oliva, M., Gonzales de Canales, M.L., Gravato, C., Guilhermino, L., Perales, J.A., 2010. 716 Biochemical effects and polycyclic aromatic hydrocarbons (PAH) in Senegal sole (Solea 717 senegalensis) from a Huelva estuary (SW Spain). Ecotoxicol. Environ. Saf. 73: 1842-1851.

719 Oliveira, M., Pacheco, M., Santos, M.A., 2008. Organ specific antioxidant responses in 720 Golden grey mullet (Liza aurata) following a short-term exposure to phenanthrene. Sci. Tot. Environ. 396: 70-78.

722

Paglia, D.E., Valentine, W.N., 1967. Studies on the quantitative and qualitative characterization of erythrocyte glutathione peroxidase. J. Labo. Clinic. Med. 70: 158-169.

Pan, L., Ren, J., Liu, J., 2005. Effects of benzo(k)fluoranthene exposure on the biomarkers of

727 728 729 column. J. Chromatogr., A 1118: 82-84. 
741 1424. 921.

Sies, H., 1999. Glutathione and its role in cellular functions. Free Rad. Biol. Medic. 27: 916-

Singer, M.M., Aurand, D., Bragin, G.E., Clark, J.R., Coelho, G.M., Sowby, M.L., Tjeerdema, R.S., 2000. Standardization of the preparation and quantitation of wateraccommodated fractions of petroleum for toxicity testing. Mar. Poll. Bull. 40: 1007-1016.

Sun, Y., Yu, H., Zhang, J., Yin, Y., Shi, H., Wang, X., 2006. Bioaccumulation, depuration and oxidative stress in fish Carassius auratus under phenanthrene exposure. Chemosphere 63: $1319-1327$.

Swannell, R.P.J., Daniel, F., 1999. Effect of dispersants on oil biodegradation under simulated marine conditions. Proceedings of the 1999 International Oil Spill Conference, Seattle, Washington, USA, pp. 169-176.

Thiem, A., 1994. Degradation of polycyclic aromatic hydrocarbons in the presence of synthetic surfactants. Appli. Environ. Microbiol. 60: 258-263.

Thomaz, J.M., Martins, N.D, Monteiro, D.A., Rantin, F.T., Kalinin, A.L., 2009. Cardiorespiratory function and oxidative stress biomarkers in Nile tilapia exposed to the organophosphate insecticide trichlorfon (NEGUVON®). Ecotoxicol. Environ. Saf. 72: 1413- 
774

775

\section{8}

Tsangaris, C., Papathanasiou, E., Cotou, E., 2007. Assessment of the impact of heavy metal pollution from a ferro-nickel smelting plant using biomarkers. Ecotoxicol. Environ. Saf. 66: 232-243.

Vandeputte, C., Guizon, I., Genestie-Denis, I., Vannier, B., Lorenzon, G., 1994. A microtiter plate assay for total glutathione and glutathione disulfide contents in cultured/isolated cells: performance study of a new miniaturized protocol. Cell Biol. Toxicol. 10: 415-421.

Van der Oost, R., Beyer, J., Vermeulen, N.P.E., 2003. Fish bioaccumulation and biomarkers in environmental risk assessment: a review. Environ. Toxicol. Pharmacol. 13: 57-149.

Winston, G.W., Di Giulio, R.T., 1991. Prooxidant and antioxidant mechanisms in aquatic organisms. Aquat. Toxicol. 19: 137-161.

Zhang, J.F., Wang, X.R., Guo, H.Y., Wu, J.C., Xue, Y.Q., 2004. Effects of water-soluble fractions of diesel oil on the antioxidant defences of the goldfish, Carassius auratus. Ecotoxicol. Environ. Saf. 58: 110-116. 